\title{
A Comparative Study on the Milling Speed for the Synthesis of Nano- Structured Al 6063 Alloy Powder by Mechanical Alloying
}

\author{
Hafeez Ahamed and V. Senthil Kumar* \\ Department of Production Engineering, National Institute of Technology, Thiruchirappalli- \\ 620015, India. \\ *Corresponding Author: vskumar@nitt.edu
}

\begin{abstract}
The present article reports on characterization studies performed on amorphized nanostructured Al 6063 alloy powder synthesized by mechanical alloying (MA). The as-milled powder was characterized by X-ray diffraction (XRD) for investigating the development of crystallite nature and determining the different phases of the materials present, scanning electron microscope (SEM) was used for in depth morphological study and High Resolution-transmission electron microscope (HR-TEM) was employed to ensure the development of a nano-structured nature of the Al 6063 matrix. In the present work alloyed powder was milled for $20 \mathrm{~h}$ and $40 \mathrm{~h}$ at $300 \mathrm{rpm}$; and $20 \mathrm{~h}$ at $700 \mathrm{rpm}$ in a hardened stainless steel medium. Using Williamson-Hall equation; crystallite size, lattice strain and lattice parameter of Al 6063 nanostructure alloy powder was estimated with broadening of XRD peaks. XRD results showed that the crystallite size of Al 6063 alloy powder reached 32 and $53 \mathrm{~nm}$ after $20 \mathrm{~h}$ at $700 \mathrm{rpm}$ and $40 \mathrm{~h}$ at $300 \mathrm{rpm}$ respectively.
\end{abstract}

Keywords: Nano-structured; Al 6063; Synthesis.

\section{INTRODUCTION}

Nano-structured metals and alloys, with average and range of grain sizes typically smaller than $100 \mathrm{~nm}$, have been the subject of considerable research in recent years. Such interest has been spurred by progress in the processing of materials and by advances in characterization techniques for complete understanding of the structural and physical properties of the recent advanced metallic nano-materials [1].In metallurgical research, X-ray diffraction, scanning electron 
microscopy (SEM) and high resolution transmission electron microscopy (HR-TEM) are the powerful tools needed for complete understanding of the grain refinement of metallic nanomaterials obtained by mechanical alloying (MA) [2]. Recent experiments have concluded that the crystallite size and the lattice strain in nano-structured samples contributes significantly with modified mechanical, physical, and electronic properties [3].

In high-energy ball milling [HEBM], plastic deformation, cold-welding and fracture are predominant factors, in which the deformation leads to a change in particle shape, cold-welding leads to an increase in particle size and fracture leads to decrease in particle size resulting in the formation of fine dispersed alloying particles in the grain-refined soft matrix [4]. As a result of HEBM, morphological and structural changes like decrease in the crystallite size, decrease in the lattice parameter and the gradual increase in the lattice strain occurs in severely deformed powder[5,6]. The lattice strain in the face centered cubic materials subjected to HEBM was found to increase continuously with decreasing crystallite size and reaches a maximum value at the smallest crystallite size [7]. Crystallite size and the lattice strain of face centered cubic nanostructured materials obtained through HEBM can be conveniently determined by WilliamsonHall analysis [8].

In the present paper nano-structured aluminium 6063 (Al 6063) alloy powder was prepared by MA. The effect of vial speed with milling time on powder structure was investigated. Hence, an attempt has been made for evaluating the crystallite size, lattice strain and lattice parameter of mechanically alloyed powders by Williamson-Hall analysis and confirmed through HRTEM.

\section{EXPERIMENTAL DETAILS}

\subsection{Materials}

The chemical composition of elemental powders and its size used in this study to make Al 6063 alloy powder in a planetary ball mill supplied by the Kemphasol Ltd., Mumbai, India are shown in Table 1.

\subsection{Processing}

The MA was executed in a two station planetary ball mill (supplied by Insmart systems Ltd., Hyderabad, India) with the following parameters:

i. ball-to-powder weight ratio: 10:1; ball diameter: $16 \mathrm{~mm}$; ball and vial material: hardened stainless steel; speed: $300 \mathrm{rpm}$. The composite powder was milled up to $40 \mathrm{~h}$ to reach steady state condition. 
ii. ball-to-powder weight ratio: 10:1; ball diameter:16 mm; ball and vial material: hardened stainless steel; speed: $700 \mathrm{rpm}$. The composite powder was milled up to $20 \mathrm{~h}$ to reach steady state condition.

The milling was performed under Toluene as the process control agent (PCA) to avoid the formation of inter-metallic compounds during milling. The high-energy wet ball milling was stopped periodically for every 15 minutes and then resumed for 15 minutes, in order to avoid significant temperature rise.

Table 1. Nominal chemical composition and mesh size used to make $\mathrm{Al} 6063$ alloy powder

\begin{tabular}{clll}
\hline Sl. No. & Name of the Elements & Wt.\% & Mesh size \\
\hline 1 & Chromium & 0.1 & -200 to -325 \\
2 & Copper & 0.1 & -325 \\
3 & Iron & $0.35 \mathrm{max}$ & -325 \\
4 & Silicon & $0.2-0.6$ & -325 \\
5 & Zinc & 0.1 & -325 \\
6 & Magnesium & $0.45-0.9$ & -200 to -325 \\
7 & Manganese & 0.1 & -200 to -325 \\
8 & Titanium & 0.1 & -200 to -325 \\
9 & Aluminium & Balance & -325 \\
\hline
\end{tabular}

\subsection{Powder Characterization}

$\mathrm{X}$-ray diffraction analysis was carried out to determine the crystallite size, lattice strain, lattice parameter and phase analysis of the milled powder samples on D/MAX Ultima III, XRD machine (Rigaku Corporation, Japan). The samples were exposed continuously to $\mathrm{Cu}-\mathrm{K}_{\alpha}$ radiation $(\lambda=1.5406 \AA$ ) operated at $40 \mathrm{kV} / 30 \mathrm{~mA}$ and at a scanning speed of $2 \% \mathrm{~min}$ for a scanning range of $20-100^{\circ}$ in steps of 0.02 .

The morphology of powder particles was investigated by scanning electron microscopy (SEM) using HITACHI S 3000H. JEOL 3010 high-resolution transmission electron microscope was used for investigating the nano-structured nature of the nano-composite powder. Particle size distribution was determined by LASER diffraction (Bluewave, Microtrac), connected to a computer that makes the volume size distribution calculation automatically. 


\section{RESULTS AND DISCUSSION}

The XRD pattern of Al 6063 nano-structured powder is shown in Fig.1. The longer milling time caused broadening of all the $\mathrm{Al}$ peaks indicating a decrease in the crystallite size and an increase in the lattice strain. The diffraction patterns of the nano-structured samples exhibited various peaks corresponding to the face centered cubic phase of Al. Al peaks are indexed using JCPDS file number 04-0787. The absence of other peaks of the alloying matrix elements can be attributed to the limitation of the filtered X-ray to detect phases with amount less than $2 \%$ volume fraction [9]. Assuming lattice strain to be uniform in all crystallographic directions, $\mathrm{X}$ ray diffraction line broadening was studied using following Williamson-Hall [10] uniform deformation equation.

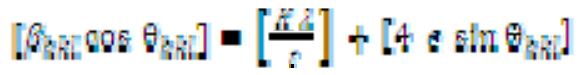

where $K$ is the shape factor (0.9), $\lambda$ is the X-ray wavelength $(1.5406 \AA), \Theta_{k k l}$ is the Bragg angle and $t$ is the effective crystallite size normal to the reflecting planes and $\varepsilon$ is the lattice strain. The instrumental corrected broadening, $\beta_{k k l}$, as a full width at half-maximum (FWHM) was approximated by a Gaussian fit, which was calculated by using X-Ray Diffraction Analysis software based on each diffracting angle of $2 \theta$. The first four most intensive reflection peaks of Al reflecting planes $\left(\begin{array}{lll}1 & 1 & 1\end{array}\right),\left(\begin{array}{lll}2 & 0 & 0\end{array}\right),\left(\begin{array}{lll}2 & 2 & 0\end{array}\right)$ and $\left(\begin{array}{lll}3 & 1 & 1\end{array}\right)$ were used to construct a linear plot of

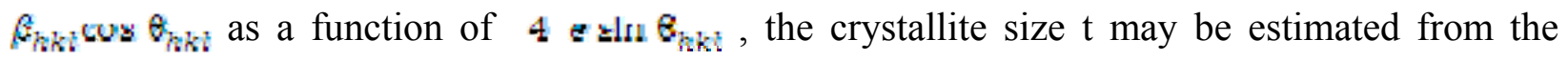
intersection with the vertical axis $\left[\frac{F L}{t}\right]$ and the lattice strain $\varepsilon$ from the slope of the line [10].

During the continuous severe plastic deformation, a continuous refinement of the internal structure of the powder particles to nanometer scale has occurred. From the Fig. 2(a) and (b), it is clear that the crystallite size of Al particle has decreased with an increase in the lattice strain. Hence it is noteworthy to say that the utilization of kinetic energy of the high density steel balls as a function of their mass and velocity with varying milling speed has affected the crushing and amorphization of the crystallite size reduction. The reduction in crystallite size was due to the creation of a large numbers of linear defects particularly dislocations which resulted in formation of high dislocation density regions within the grains. During further milling the sample volume exhibiting small grains extends throughout the entire specimen, hence decreasing the effective crystallite size [11].Decreased lattice strain was observed in the sample milled for $40 \mathrm{~h}$ at $300 \mathrm{rpm}$ under investigation. Alternatively the increased lattice strains in the sample milled for $20 \mathrm{~h}$ at 700rpm could be due to excess volume of grain boundaries associated with dislocations or due to dislocations. The aluminium crystallite size and lattice strain based on Williamson-Hall analysis method for as-milled nano-structured powders are presented in Table2. Fig.2(c) showing SEM 
micrograph confirms almost spherical shaped particles which is the characteristics of the steady state milling condition in the sample milled for $40 \mathrm{~h}$ at $300 \mathrm{rpm}$.
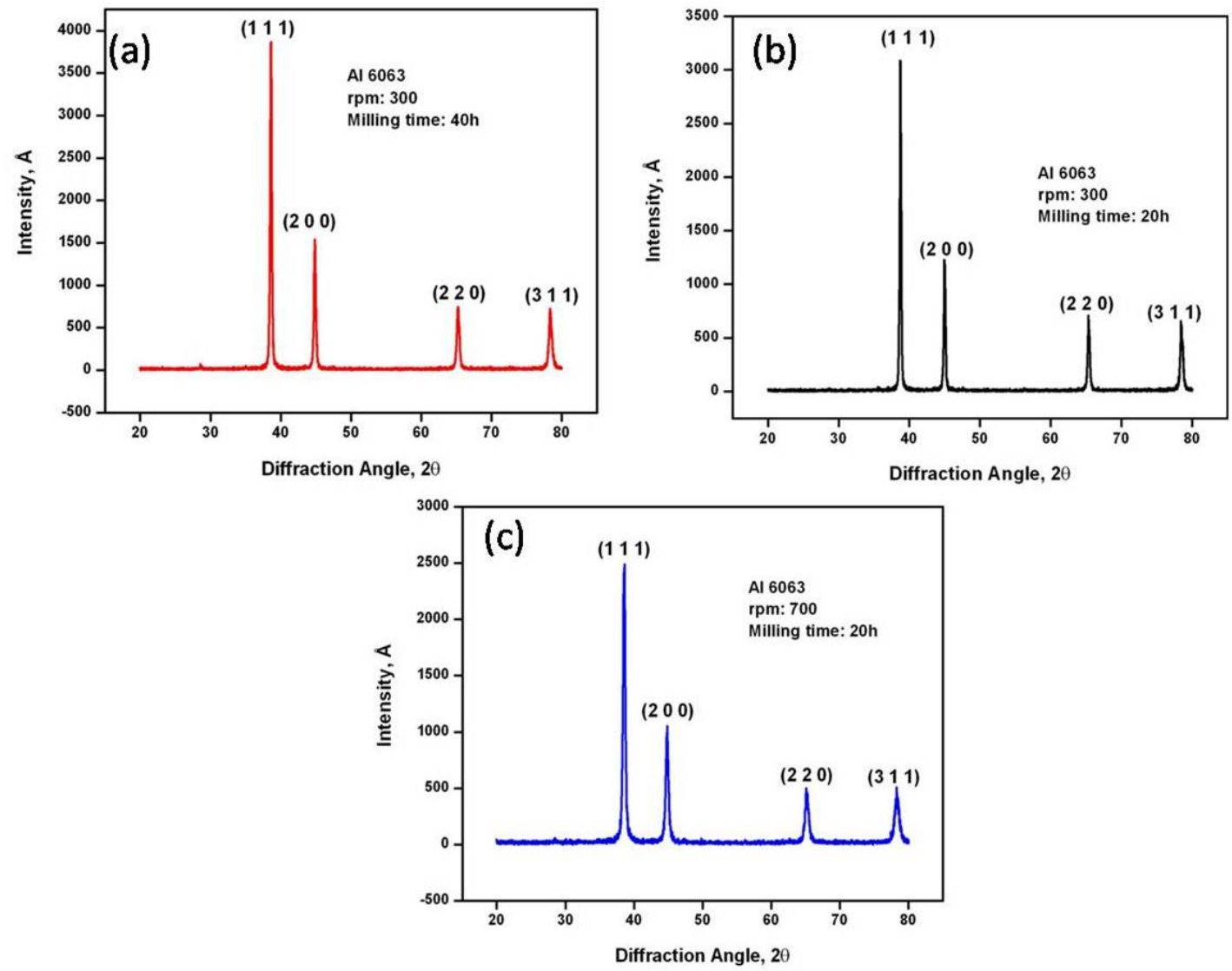

Fig. 1. XRD patterns of Al 6063 powder after (a) $40 \mathrm{~h}$ at $300 \mathrm{rpm} \mathrm{(b)} \mathrm{)} 20 \mathrm{~h}$ at $300 \mathrm{rpm}$ (c) $20 \mathrm{~h}$ at $700 \mathrm{rpm}$, showing the variation of sharp diffraction peaks of Al getting broadened and reduced in intensity.

Table 2. Grain size, lattice strain and lattice parameter of $\mathrm{Al}$ 6063powder.

\begin{tabular}{lccc}
\hline Parameter & Grain Size in nm & Lattice Strain in \% & Lattice Parameter in $\AA$ \\
\hline $\begin{array}{l}20 \mathrm{~h} ; \\
700 \mathrm{rpm}\end{array}$ & 32 & 0.27 & 0.4046 \\
\cline { 1 - 1 } $\begin{array}{l}20 \mathrm{~h} ; \\
300 \mathrm{rpm}\end{array}$ & 55.46 & 0.16 & 0.4045 \\
\cline { 1 - 1 } $\begin{array}{l}40 \mathrm{~h} ; \\
300 \mathrm{rpm}\end{array}$ & 53.12 & 0.21 & 0.4046 \\
\hline
\end{tabular}



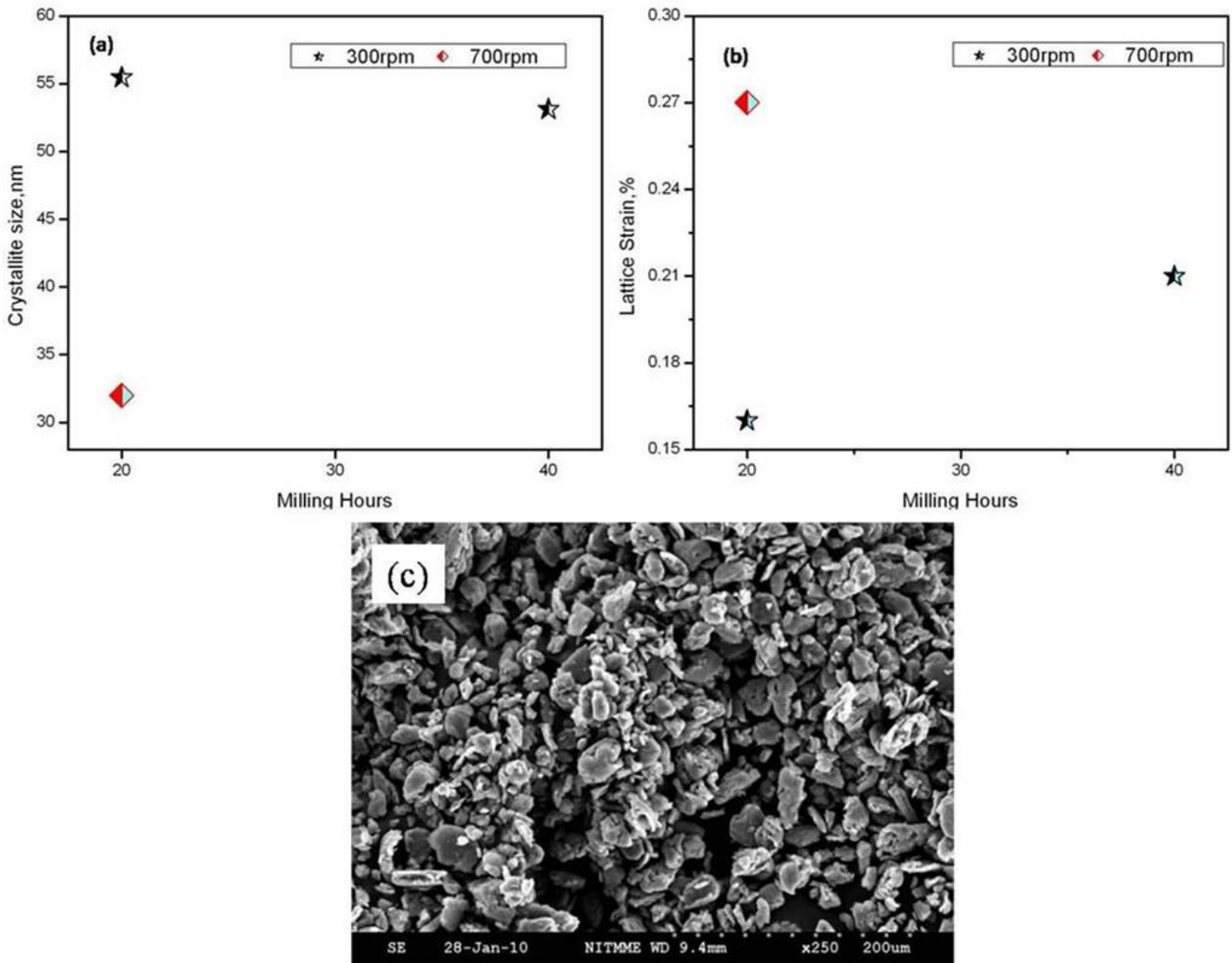

Fig. 2. Effect of milling time and speed on (a) crystallite size and (b) lattice strain (c) SEM micrograph showing the morphology of $\mathrm{Al} 6063$ powder after $40 \mathrm{~h}$ milling at $300 \mathrm{rpm}$.

Particle size distributions of $\mathrm{Al} 6063$ powder is shown in Fig.3. After $40 \mathrm{~h}$ of milling the particle size distribution of Al 6063 at $300 \mathrm{rpm}$ shown in Fig.3(b) broadens as compared to the asreceived aluminium powder shown in Fig.4(a). The average particle size of Al 6063 alloy sample after $40 \mathrm{~h}$ of MA recorded by Laser scattering system was $30.51 \mu \mathrm{m}$ (Fig.4(b)) where as the average particle size of as-received aluminium powder was $28.69 \mu \mathrm{m}$. The broader particle size distribution is due to the predominance of particle deformation, while the increase in equivalent diameter size indicates the occurrence of welding between matrix particles. The particle size distribution shown in Fig.4(b)) is asymmetric with a deviation of the size distribution to the right indicates particles welding with themselves and other alloying matrix elements. 

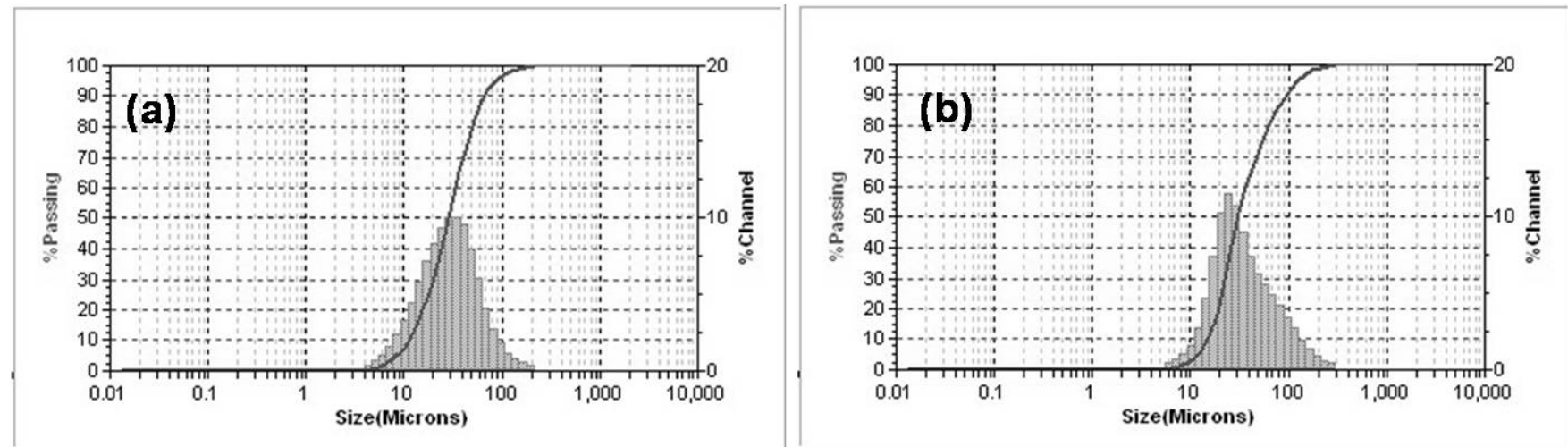

Fig. 3. Particle size distributions of Al 6063 powders (a) as-received (b) milled for $40 \mathrm{~h}$ at 300 rpm.

Lattice parameter at $40 \mathrm{~h}$ of milled powder was estimated by constructing the linear plot between the calculated lattice parameter for each Bragg's angle on the y-axis and the corresponding value

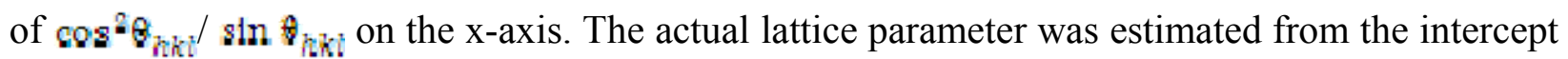
as explained by B.D. Cullity [9]. Reductions in lattice parameter for powders under investigation with respect to milling time are given in Table2. It was noticed that the lattice parameter decreases with increasing milling time, suggesting the formation of Al-based solid solutions. The observed decrease in the lattice parameter is consistent with the possible formation of $\mathrm{Al}$ solid solutions with $\mathrm{Fe}, \mathrm{Cr}, \mathrm{Cu}, \mathrm{Mg}, \mathrm{Ti}, \mathrm{Si}, \mathrm{Zn}, \mathrm{Mn}$, and $\mathrm{O}$ elements. The dissolution of $\mathrm{Fe}, \mathrm{Cr}$, $\mathrm{Cu}, \mathrm{Mg}, \mathrm{Ti}, \mathrm{Si}, \mathrm{Zn}, \mathrm{Mn}$ and $\mathrm{O}$ elements into $\mathrm{Al}$ will decrease the lattice parameter of $\mathrm{Al}$, because the atomic sizes of $\mathrm{Fe}, \mathrm{Cr}, \mathrm{Cu}, \mathrm{Si}, \mathrm{Zn}, \mathrm{Mn}$ and $\mathrm{O}$ elements are smaller than that of $\mathrm{Al}$, whereas the atomic size of $\mathrm{Ti}$ and $\mathrm{Mg}$ is similar to that of $\mathrm{Al}$ [12].

Fig.4 shows HR-TEM image of mechanically alloyed Al 6063 nano-structured powders showing crystallinity is maintained right up to the boundary and no inter-metallic compound/layer formed in $\mathrm{Al}$ matrix showing lattice fringes after $40 \mathrm{~h}$ of high-energy wet ball milling. The inset in the figure represents the selected area diffraction pattern showing only diffuse intensity halo due to an amorphous microstructure. The bright areas in the micrograph correspond to coarse crystallites. The crystallite size calculated from X-ray peak broadening and absence of other peaks indicating no formation of intermetallic layer are in close agreement with that of HR-TEM observations. 


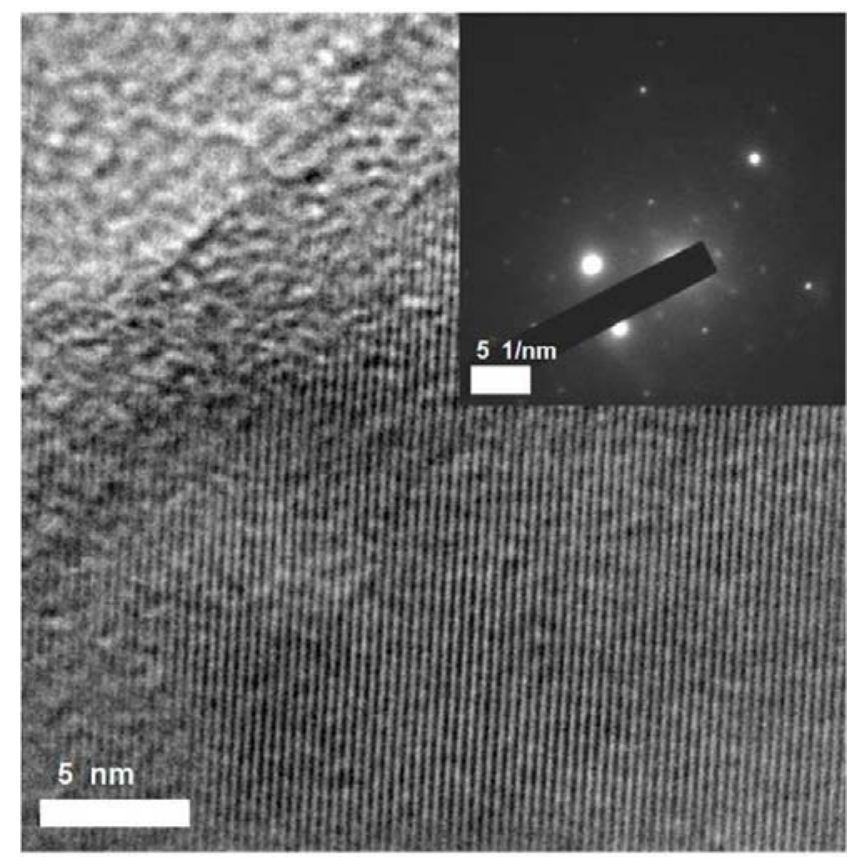

Fig. 4. HR-TEM image of mechanically alloyed Al 6063 nano-structured powders showing crystallinity is maintained right up to the boundary and no inter-metallic compound/layer formed in $\mathrm{Al}$ matrix showing lattice fringes after $40 \mathrm{~h}$ of milling. Inset is the selected area diffraction pattern of the same alloy showing only diffuse intensity halo due to an amorphous microstructure.

\section{CONCLUSIONS}

- Nano-structured Al 6063 alloy powder in amorphized state was successfully obtained by MA.

- Williamson-Hall analysis assuming uniform deformation model was successfully employed for evaluating the crystallite size and understanding strain present in the nanostructured powder obtained through MA.

- Low kinetic energy of balls at 300rpm and long milling time of $40 \mathrm{~h}$ resulted in reduced lattice strain as compared to high kinetic energy of balls at $700 \mathrm{rpm}$ for short milling time of $20 \mathrm{~h}$.

\section{ACKNOWLEDGEMENTS}

The authors thank the Institute for the project grant to carry out the investigation. The facilities made available under DST project (SR/FTP/ETA/-69/07), Government of India, are gratefully acknowledged. In addition, the author (Hafeez Ahamed) would like to express his gratitude to Director, Department of Technical Education, Karnataka, and All India Council for Technical Education (AICTE) in India for sponsoring and support during his doctoral studies. 


\section{REFERENCES}

[1] K. S. Kumar, H. Van Swygenhoven, S. Suresh, Mechanical behavior of nanocrystalline metals and alloys, Acta Mater 2003, 5743-5774.

[2] K. Ramakanth. Basics of X-ray Diffraction and its Application, New Delhi, I. K. International Publishing House; 2007.

[3] V. Viswanathan, T. Laha, K. Balani, A. Agarwal, S. Seal, Challenges and advances in nanocomposite processing techniques, Mater Sci Eng R 2006, 121-285.

[4] C. Suryanarayana, Mechanical alloying and milling, Prog Mater Sci 2001, 1-184.

[5] Viseslava Rajkovic, Dusan Bozic, Milan T. Jovanovic, Characterization of prealloyed copper powders treated in high energy ball mill, Mater Charact 2006, 94-99.

[6] Maryam Azabou, Mohamed Khitouni, Abdelwaheb Kolsi, Characterization of nanocrystalline Al-based alloy produced by mechanical milling followed by cold-pressing consolidation, Mater Charact 2009, 499 - 505.

[7] C. C. Koch. Synthesis of nanostructured materials by Mechanical milling: problems and opportunities, Nano Structured Materials, Nanostruct Mater 1997, 13-22.

[8] V. Biju, Neena Sugathan, V. Vrinda, S. L. Salini. J Mater Sci 2008, 1175-1179.

[9] B. D. Cullity. Elements of X-ray diffraction, third ed., London, Prentice Hall; 2001.

[10] K. Williamson, W. H. Hall, X-ray line broadening from filed aluminium and wolfrom, Acta Metall. 1953, 22-31.

[11] H. J. Fecht, Nanostructure formation by Mechanical attrition, Nanostruct Mater 1995, 33 42.

[12] P. Haasen, Physical Metallurgy, 3rd Ed., Cambridge University Press Cambridge, Great Britain, 1996. 